\title{
Testicular shear wave elastography in oligo-astheno-teratozoospermic individuals: a prospective case-control study
}

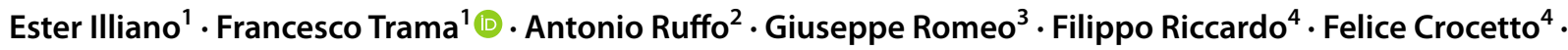 \\ Fabrizio lacono ${ }^{4}$. Elisabetta Costantini ${ }^{1}$
}

Received: 14 January 2021 / Accepted: 31 May 2021 / Published online: 10 June 2021

(c) The Author(s) 2021

\begin{abstract}
Purpose The primary objective of this study was to evaluate the testicular stiffness by ultrasound shear wave elastography (SWE) both in men with oligo-astheno-teratozospermia (OAT) and in control group. The secondary objective was to identify a possible correlation between semen quality with testicular stiffness.

Methods This was a prospective case-control study. We divided the sample in two groups; Group A (case group) included men with OAT, and Group B (control group) men with normal sperm parameters. All participants had at last two semen analysis in the past 180 days (at last 90 days apart), using performed ultrasound and SWE elastography.

Results We analyzed 100 participants, 50 patients in Group A and 50 controls in Group B. There were statistically significant differences in term of testicular volume and testicular stiffness between two groups. Men with OAT had the testicular stiffness value higher than the controls in both sides (left testicular stiffness $21.4 \pm 5.4 \mathrm{kPa}$ vs $9.9 \pm 1.6 \mathrm{kPa}, p<0.0001$; right testicular stiffness $22.9 \pm 4.8 \mathrm{kPa}$ vs $9.5 \pm 2.4 \mathrm{kPa}, p<0.0001)$. Men with abnormal semen parameters showed an inverse correlation between the mean value of testicular stiffness and total sperm count $(22.15 \pm 3.38 \mathrm{kPa}, r=-0.387, p=0.005)$, sperm concentration $(22.15 \pm 3.38 \mathrm{kPa}, r=-0.244, p=0.04)$, and progressive motility $(22.15 \pm 3.38 \mathrm{kPa}, r=-0.336, p=0.01)$, while the correlation was not evident in controls group.
\end{abstract}

Conclusion SWE is able to differentiate between testicles with spermatogenic changes from a healthy testicle. For this reason, it could be used to evaluate, in a non-invasive way, the tissue alterations of the organ.

Keywords Shear wave elastography $\cdot$ Oligo-astheno-teratozoospermia $\cdot$ Male infertility $\cdot$ Testicular stiffness

\section{Introduction}

Infertility is estimated to affect between 8 and $12 \%$ of reproductive-aged couples worldwide [1]. Approximately $40 \%$ of all male infertility cases are mainly caused by sperm defects

Francesco Trama

francesco.trama@studenti.unipg.it

Ester Illiano

ester.illiano@inwind.it

Antonio Ruffo

antonio.ruffo7@gmail.com

Giuseppe Romeo

giuseppe.romeo85@gmail.com

Filippo Riccardo

filippo.riccardo@gmail.com

Fabrizio Iacono

fiacon@tin.it
[2]. Oligo-astheno-teratozoospermia syndrome (OAT) is defined as the presence of oligozoospermia $(<15$ million spermatozoa/mL), asthenozoospermia $(<32 \%$ progressive motile spermatozoa), and teratozoospermia ( $<4 \%$ normal forms).

\section{Elisabetta Costantini}

elisabetta.costantini@unipg.it

1 Andrology and Urogynecology Clinic, Santa Maria Terni Hospital, University of Perugia, Viale Tristano di Jannuccio 1 Terni, Perugia, Italy

2 Andrea Grimaldi Hospital, San Giorgio a Cremano (NA), Naples, Italy

3 Urology Department, A.O.R.N. A. Cardarelli, Naples, Italy

4 Department of General and Specialized Surgeries, Renal Transplantation, Nephrology, Intensive Care and Pain Management, University of Federico II, Naples, Italy 
In the diagnostic work-up of OAT syndrome, B-mode ultrasonography is used specifically in the measurement of testicular volume and echogenicity, and in the detection of possible varicocele, seminal vesicle abnormalities, and abnormalities in the conformation of the epididymis [3].

Ultrasound (US) shear wave elastography (SWE) has been widely used in the past few years in the andrological field. It is an imaging modality that allows the evaluation of tissue stiffness based on the trajectory of shear wave propagation through a structure [4]. SWE, in which an ultrasonic pulse is applied to the tissue in SWE, induces the formation of transverse waves arranged perpendicularly to the direction of the ultrasound beam [5]. Higher shear wave velocities correspond to harder tissue. Using SWE, a quantitative measurement of the stiffness of a tissue is obtained by calculating the modulus of elasticity (or Young's modulus) expressed in Kilopascal (kPa) or meter per second $(\mathrm{m} / \mathrm{s})$ [5].

SWE is used to investigate testicular pathologies, in particular neoplastic processes [6], infarction [7], torsion [8], varicocele [9], and orchitis [10]. There are only a few previous studies in the literature that have investigated the relationship between SWE values and defects of semen quality $[11,12]$.

The primary aim of our study was to analyze testicular stiffness in both the control and OAT groups. The secondary aim of this study was to correlate testicular stiffness with testicular volume and to identify a possible correlation of SWE values with semen quantity and quality.

\section{Materials and methods}

This study was a prospective case-control study. The study was approved by the local ethics committee (CER 3767/20) and each participant included in the study signed an informed consent to participate in the study. The study was conducted in accordance with the Privacy Act and in accordance with the Declaration of Helsinki in all applicable aspects.

We divided the participants into two groups: Group A (case group) included males aged $>18$ years with abnormal semen parameters; in particular, all participants had OAT syndrome according to the WHO 2010 criteria [13].

Group B (control group) included healthy male participants $>18$ years of age who underwent testicular ultrasound for unrelated reasons and who had no alteration of seminal parameters, or no testicular affections.

Exclusion criteria were obstructive azoospermia (OA) and non-obstructive azoospermia (NOA), presence of monorchid, varicocele, hydrocele, urogenital infections, history of testicular tumors or twisting of the funiculus, history of cryptorchidism, previous genital surgery in the past 12 months, and Klinefelter syndrome.
In both the groups, we gathered a detailed clinical history and performed local examination, US, and SWE elastography. All SWE procedures were performed by a single urologist (who had 3 years of experience in SWE elastography) in a dedicated room. Another senior urologist with 5 years of experience in SWE elastography verified the data in the picture archive and communications system (PACS) to ensure that the measurements were accurate. The ultrasound scanner with the integrated SWE module [General Electric (GE) Logiq S8, Chicago, USA] and a linear probe (7.5-13.5 MHz) was used.

In mode $\mathrm{B}$, the testicular volumes were measured by applying the ellipsoid formula [length $\times$ height $\times$ width $\times 0$. 523]. Then, SWE was performed. The stiffness values were calculated separately for the two testicles. Each testicle was divided into three parts (Fig. 1): 1/3 upper pole (Fig. 1a), 1/3 central region (Fig. 1b), and 1/3 lower pole (Fig. 1c). The measurement was performed in the axial plane by affixing a region of interest (ROI). Each ROI provided a mean shear wave stiffness value in $\mathrm{kPa}$. We then calculated the average of the three regions examined. The transducer was touched laterally to minimize operator-dependent pressure on the testicular region, and an ample coupling gel was used. In addition to the value calculated in $\mathrm{m} / \mathrm{s}$ and in $\mathrm{kPa}$, it was possible to see a color scale according to the stiffness: intense blue color indicates elasticity, while a deep red color indicates stiffness. Each patient was asked to hold their breath when measuring stiffness in order to reduce movement artifacts.

All participants had at least two semen analysis performed in the last 180 days (at least 90 days apart) at the same diagnostic center that complied with the WHO 2010 criteria.

Furthermore, the recommended abstinence period was 2-7 days as recommended by the 2010 WHO guidelines.

Statistical analysis was performed using the paired t-test for continuous parametric variables and the Mann-Whitney test and Wilcoxon's test for nonparametric variables. The Kolmogorov-Smirnov test was used to evaluate whether the data were normally distributed and Pearson's correlation test was used for quantitative variables. All calculations were performed using the IBM-SPSS ${ }^{\circledR}$ version 22.0 (IBM Corp., Armonk, NY, USA). We considered $p<0.05$ to indicate statistical significance.

\section{Results}

A total of 114 participants were declared eligible for the study from June 2019 to November 2020. Eleven participants did not wish to perform the proposed examination and for three participants, the measurements were not reliable due to movement artifacts. A total of 100 participants were 
Fig. 1 Testicle was divided into three parts: $1 / 3$ upper pole (a), 1/3 central region (b), 1/3 lower pole (c) and the measurement was performed in the axial plane by affixing a region of interest (ROI). Each ROI provided a mean shear wave stiffness value in $\mathrm{kPa}$ a

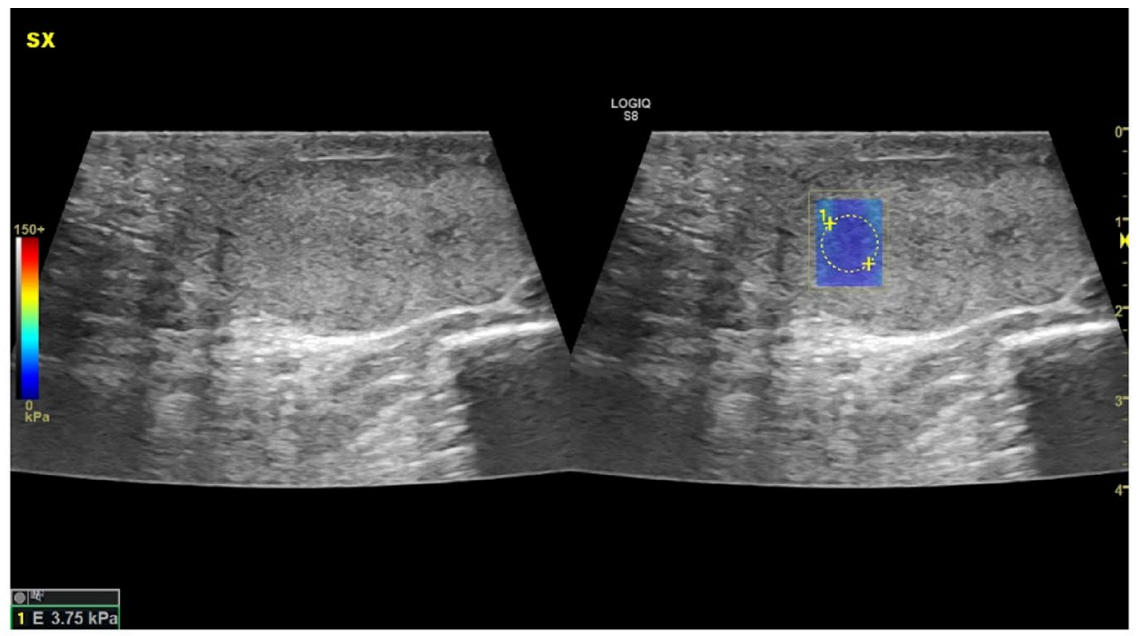

b

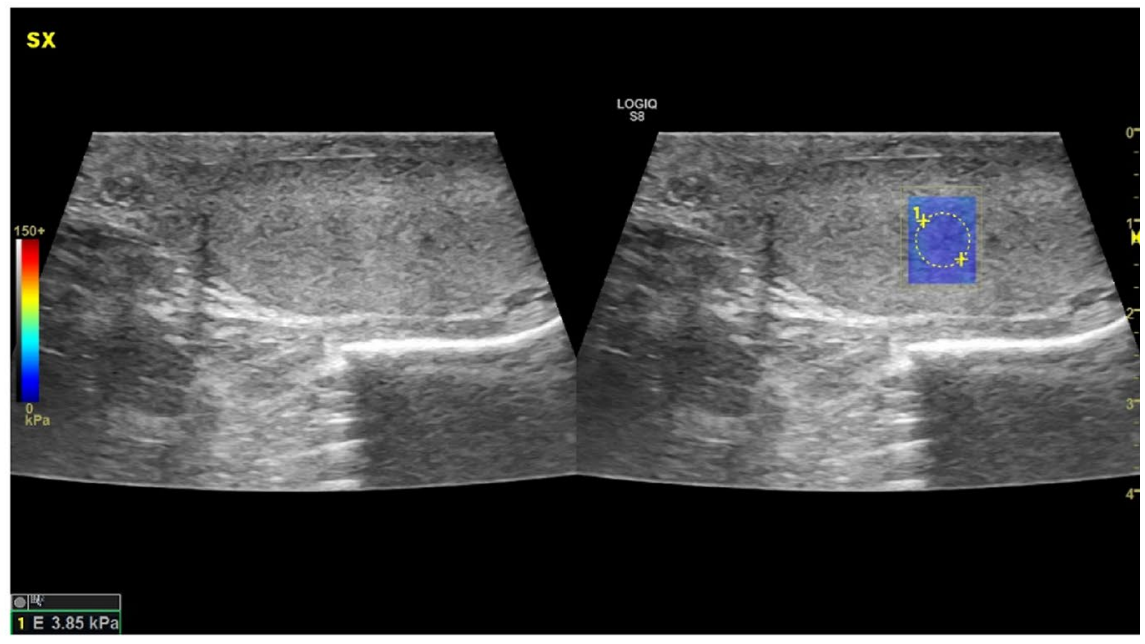

c

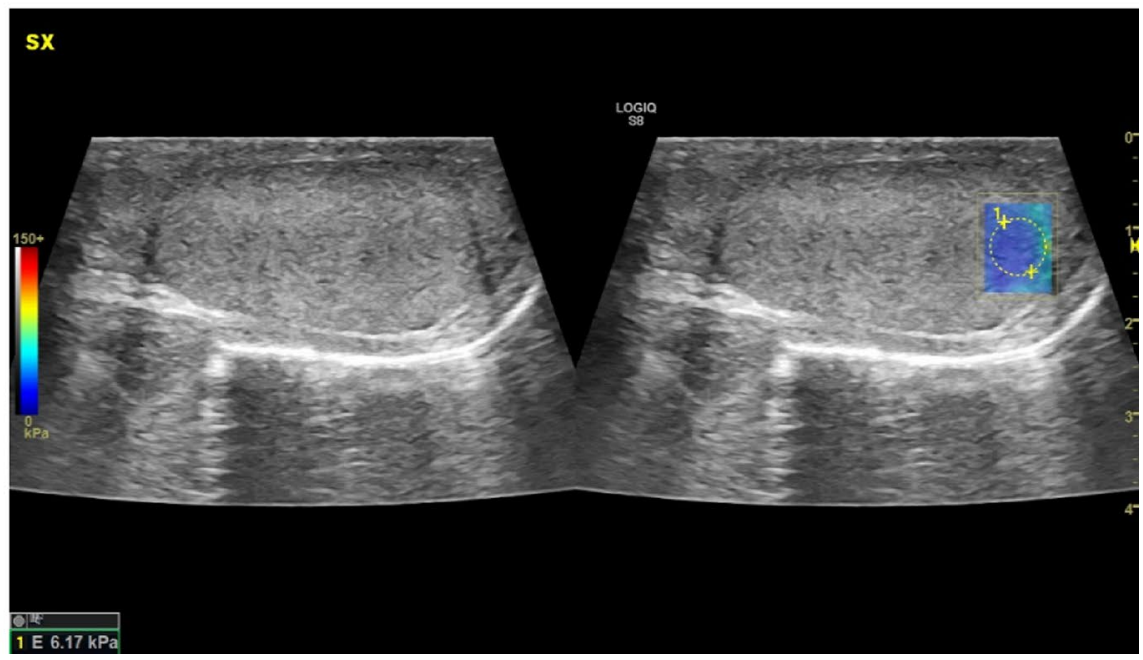

finally enrolled: 50 patients in Group A, and 50 controls in Group B.

Table 1 shows the demographic data of both the groups. The male participants in the two groups were comparable by age and BMI $(p>0.05)$. Moreover, there were no statistically significant differences between the semen parameters in both groups between the first determination and the second determination made.

Table 2 shows the seminal fluid values in groups A and B. There was a statistically significant difference $(p<0.0001)$ 
Table 1 Average age and BMI of male patients and their partners

\begin{tabular}{lllllll}
\hline & $\begin{array}{l}\text { Male mean age } \\
\text { (years) } \pm \text { SD }\end{array}$ & $p$ value & BMI $\left(\mathrm{kg} / \mathrm{m}^{2}\right) \pm \mathrm{SD}$ & $p$ value & $\begin{array}{l}\text { Female mean age } \\
\text { (years) } \pm \mathrm{SD} \text { value }\end{array}$ & \\
\hline GROUP A & $36 \pm 16.7$ & 0.970 & $25.2 \pm 6.2$ & 0.884 & $30 \pm 8$ & 0.942 \\
GROUP B & $38 \pm 17.4$ & & $25.6 \pm 5.8$ & & $30 \pm 8.2$ & \\
\hline
\end{tabular}

SD standard deviation

*Statistically significant at $p<0.05$

\begin{tabular}{llll}
\hline Parameters & Group A & Group B & $p$ value \\
\hline Normal viscosity, no pts & 35 & 38 & nd \\
Abstinence days & $3.8 \pm 1.6$ & $3.9 \pm 1.7$ & nd \\
Complete fluidification, no pts & 34 & 36 & nd \\
PH (mean \pm SD) [r.v.: pH $>7.2]$ & $8.1 \pm 0.1$ & $8.4 \pm 0.3$ & 0.219 \\
Semen volume $(\mathrm{mL}$, mean \pm SD) [r.v.: semen volume: $>1.5 \mathrm{~mL}]$ & $2.5 \pm 1.2$ & $2.9 \pm 0.9$ & 0.115 \\
Total sperm number $\left(10^{6} /\right.$ ejaculate, mean \pm SD) [r.v. total sperm & $25 \pm 9.6$ & $69.1 \pm 21.2$ & $<0.0001^{*}$ \\
$\quad$ number $>39 \times 10^{6} /$ ejaculate] & & & \\
Sperm concentration $\left(10^{6} / \mathrm{mL}\right.$, mean \pm SD) [r.v. sperm concentra- & $7.7 \pm 4.2$ & $26.2 \pm 7.7$ & $<0.0001^{*}$ \\
$\quad$ tion $>15 \times 10^{6} / \mathrm{mL}$ ] & & & \\
Progressive motility (mean \pm SD) [r.v.: PR $>32 \%]$ & $18.4 \pm 9.2$ & $48.9 \pm 10.9$ & $<0.0001^{*}$ \\
Sperm morphology (normal forms \%) [r.v. $>4 \%]$ & $2.5 \pm 1.1$ & $15.8 \pm 7.1$ & $<0.0001^{*}$ \\
\hline
\end{tabular}

$P R$ progressive motility, Pts patients, $R$.V. reference value, $n d$ not determined $* p \leq 0.05$
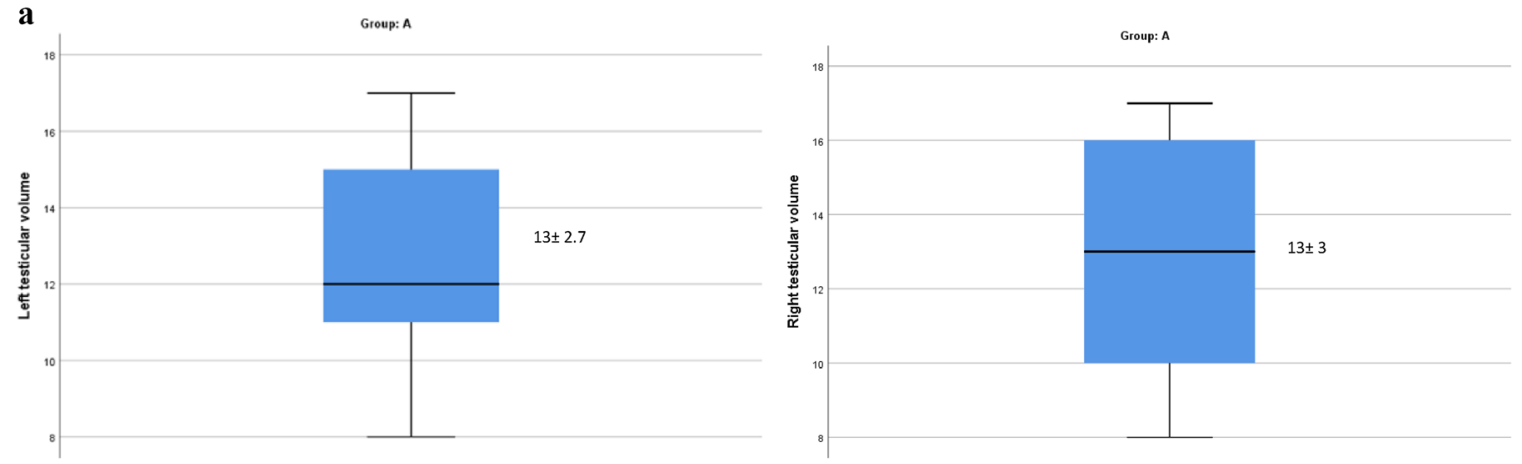

$p$ value $=0.772$
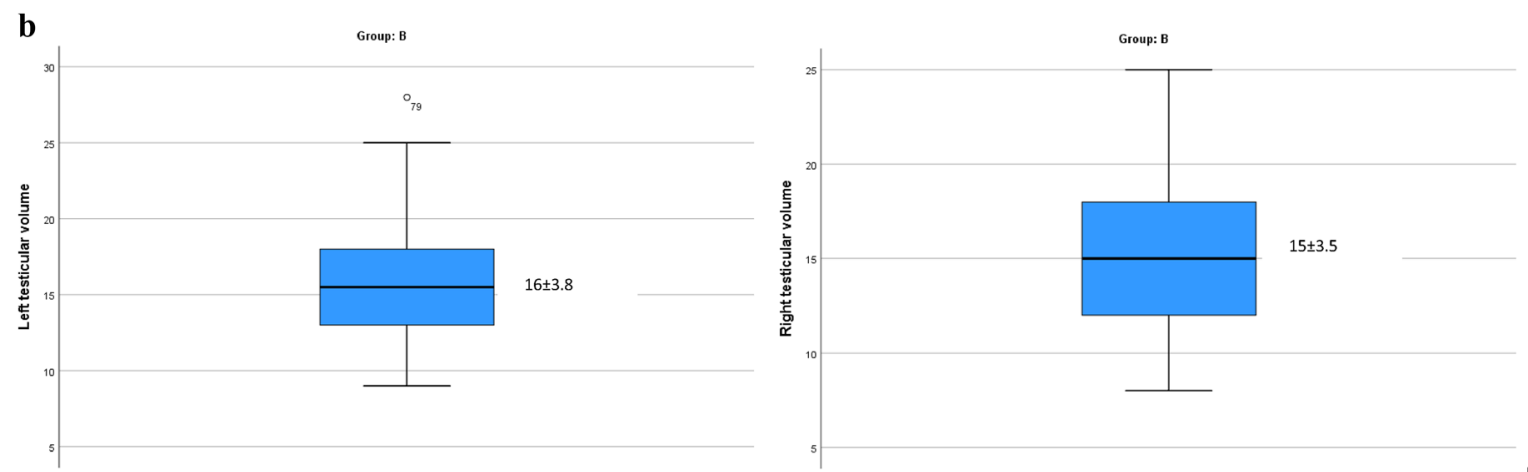

$p$ value $=0.516$

Fig. 2 a Average testicular volume analysis found in left and right group A. b Average testicular volume analysis found in left and right group B 

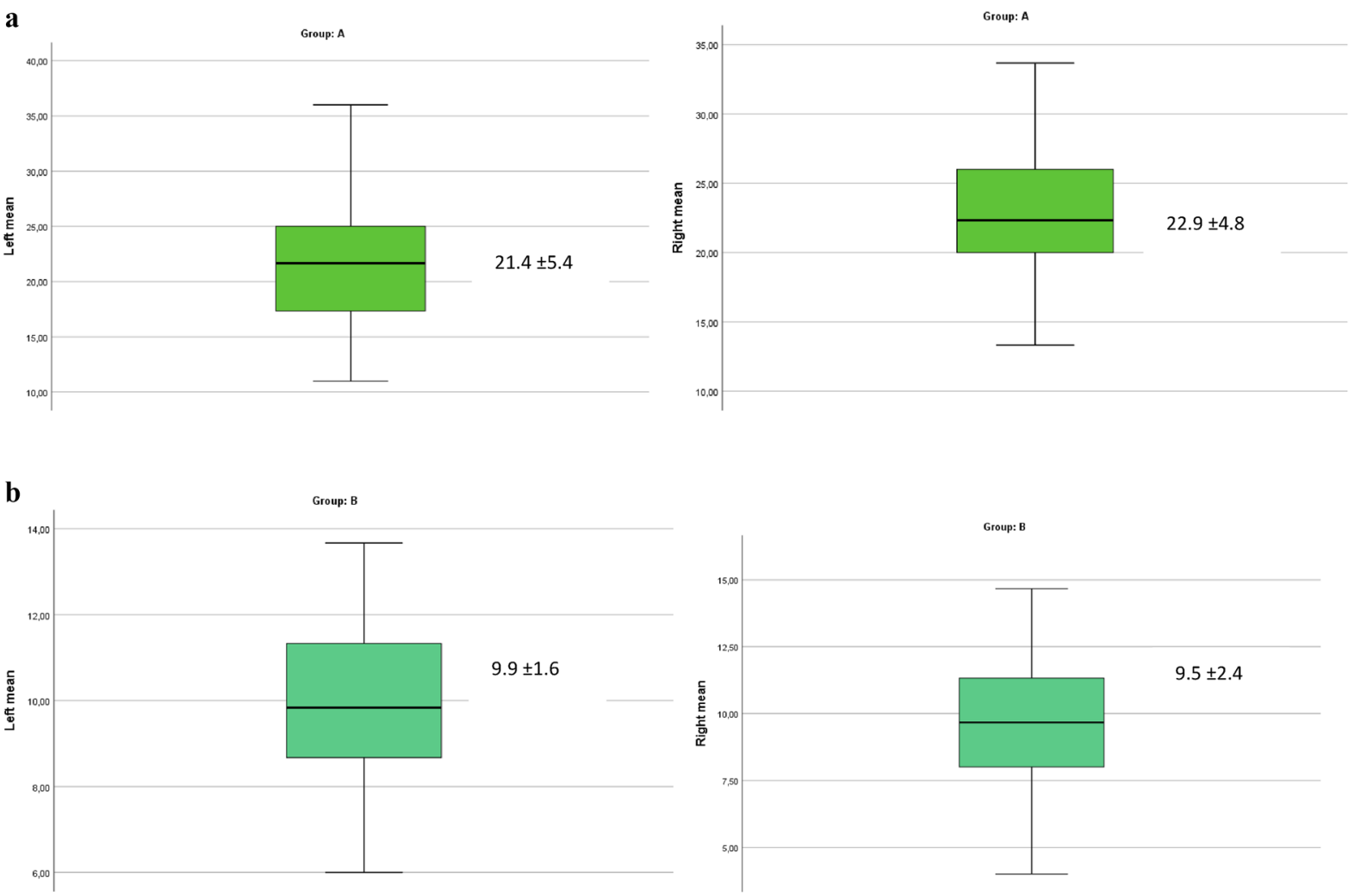

$p=0.35$

Fig. 3 a Testicular stiffness value in left and right group A. b Testicular stiffness value in left and right group B

Table 3 Comparison between the average testicular volume in group $\mathrm{A}$ and the average testicular volume in group B for both right and left sides

\begin{tabular}{|c|c|c|c|c|}
\hline & $\begin{array}{l}\text { Left testicular } \\
\text { volume[mean } \\
( \pm \text { SD)] }\end{array}$ & $p$ value & $\begin{array}{l}\text { Right testicular } \\
\text { volume [mean } \\
( \pm \text { SD)] }\end{array}$ & $p$ value \\
\hline Group A & $13 \pm 2.7$ & $<0.0001 *$ & $13 \pm 3$ & $0.001 *$ \\
\hline Group B & $16 \pm 3.8$ & & $15 \pm 3.5$ & \\
\hline
\end{tabular}

SD standard deviation

*Statistically significant at $p<0.05$

between group A and group B in terms of total sperm count (million/ejaculate), sperm concentration (million/mL), progressive motility (\%), and normal forms (\%).
Figures 2 and 3 show that, within each group, there were no statistically significant differences in terms of testicular volume and testicular stiffness between the two sides in both groups.

There was a statistically significant difference between the mean testicular volume in participants with semen quality defects and in the control group both in left $(p<0.0001)$ and in right side $(p=0.001$, Table 3$)$. In fact, group A patients had a testicular volume lower than group B patients.

In addition, the testicular stiffness value in group $\mathrm{A}$ patients was greater than the testicular stiffness value in group B patients in a statistically significant manner $(p<0.0001)$ (Table 4, Fig. 3).

In participants with abnormal semen parameters, there was an inverse correlation between the mean value of
Table 4 Comparison between left and right testicular SWE values for both right and left sides

\begin{tabular}{lllll}
\hline & $\begin{array}{l}\text { Left testicular stiffness } \\
{[\text { mean } \mathrm{kPa}( \pm \mathrm{SD})]}\end{array}$ & $p$ value & $\begin{array}{l}\text { Right testicular stiffness } \\
{[\text { mean } \mathrm{kPa}( \pm \mathrm{SD})]}\end{array}$ & $p$ value \\
\hline Group A & $21.4( \pm 5.4)$ & $<0.0001^{*}$ & $22.9( \pm 4.8)$ & $<0.0001^{*}$ \\
Group B & $9.9( \pm 1.6)$ & & $9.5( \pm 2.4)$ & \\
\hline
\end{tabular}

$S D$ standard deviation

*Statistically significant at $p<0.05$ 
Table 5 Correlation between testicular stiffness and spermiogram values of patients in groups $\mathrm{A}$ and $\mathrm{B}$

\begin{tabular}{|c|c|c|c|}
\hline Group & Mean $\mathrm{kPa} \pm \mathrm{SD}$ & $r$ & $p$ value \\
\hline \multicolumn{4}{|l|}{ A } \\
\hline Total sperm number $\left(10^{6} /\right.$ ejaculate, mean $\left.\pm \mathrm{SD}\right)$ & $22.15 \pm 3.38$ & -0.387 & $0.005^{*}$ \\
\hline Sperm concentration $\left(10^{6} / \mathrm{mL}\right.$, mean $\left.\pm \mathrm{SD}\right)$ & & -0.244 & $0.04 *$ \\
\hline Progressive motility $(\mathrm{PR}+\mathrm{NP}$, mean $\pm \mathrm{SD})$ & & -0.336 & $0.01 *$ \\
\hline Sperm morphology & & -0.085 & 0.55 \\
\hline \multicolumn{4}{|l|}{ B } \\
\hline Total sperm number $\left(10^{6} /\right.$ ejaculate, mean $\left.\pm \mathrm{SD}\right)$ & $9.7 \pm 1.6$ & -0.10 & 0.46 \\
\hline Sperm concentration $\left(10^{6} / \mathrm{mL}\right.$, mean $\left.\pm \mathrm{SD}\right)$ & & -0.07 & 0.61 \\
\hline Progressive motility $(\mathrm{PR}+\mathrm{NP}$, mean $\pm \mathrm{SD})$ & & 0.19 & 0.16 \\
\hline Sperm morphology & & -0.15 & 0.29 \\
\hline
\end{tabular}

testicular stiffness expressed in $\mathrm{kPa}$ (left and right testicle) and total sperm count $(p=0.005)$, sperm concentration $(p=0.04)$, and progressive motility $(p=0.01)$ (Table 5, Fig. 4). The correlation was not evident in the group with healthy men (Table 5).

There are no statistically significant differences between the testicular volume and the elasticity found in group A (left testicular: $p=0.240$; right testicular: $p$ value 0.331 ). In the same way, there was no statistically significant difference between the testicular volume and the elasticity found by performing SWE to the group B (left testicular: $p=0.056$; right testicular: $p$ value 0.645 ).

Table 6 showed a statistically significant difference in the mean of the variables relating to the upper right and left poles $(p<0.0001)$, lower right and left poles $(p<0.0001)$, and medial right and left $(p<0.0001)$ in the two subgroups $\mathrm{A}$ and $\mathrm{B}$.

In the Table 7 we analyzed the differences in stiffness between the upper pole, medial region, and lower pole in the same testis in both Group A and Group B; there were no significant differences $(p>0.05)$.

In Figs. 5 and 6, we have reported the frequencies of the stiffness values found in the testicular region (both left and right) in both group A and group B.

\section{Discussion}

Based on the previous literature, approximately $50 \%$ of the cases of infertility are caused due to male factors [2]. Oligoastheno-teratozoospermia syndrome (OAT) is a frequent occurrence in couples with infertility problems. Approximately $30 \%$ of all infertile men are unaware of the underlying cause of their infertility. The diagnosis of OAT is performed on the basis of semen analysis results, but the causes of OAT syndrome are complex; in fact there may be genetic, environmental or iatrogenic causes that cause alterations of semen analysis [14].

Testicular biopsy could be considered as the gold standard of investigation to understand the cause of testicular damage, but it is not always feasible due to the invasive nature, associated costs, and possible side effects [12].

If performed well and analyzed properly, the semen analysis can be a good diagnostic aid, along with the andrological examination and bilateral testicular ultrasound, in the diagnostic work-up of seminal problems in males [14].

SWE is an operator-independent method that can be easily reproduced $[15,16]$. Moreover, it can be used to obtain a quantitative value of the analyzed tissue and to eventually compare the results obtained following the targeted treatments [17].

In fact, testicular $\mathrm{kPa}$ values, which represent parenchymal elasticity, are inversely correlated with sperm values.

Moreover, in our study, the US SWE showed that in Group A, the testicular volume was lower than in the control group (Group B). Previously reported results of ultrasound evaluation of testicular volume were in agreement with ours [18]. This is in accordance with Ehala-Aleksejev et al. who found that the testicular volume measured by US examination correlated negatively with seminal parameters [19]. Erdogan et al. showed that in patients with spermatic problems, testicular SWE value was significantly higher than in patients without spermatic problems, which is in agreement with our observations. It is possible that the parenchymal damage that causes seminal fluid defects simultaneously decreases the elasticity of the testes [20]. Rocher et al. [12], however, did not find a correlation between testicular volume and stiffness value. This difference in findings could be explained by the use of different technique; the previous authors used strain elastography, whereas we performed SWE. 

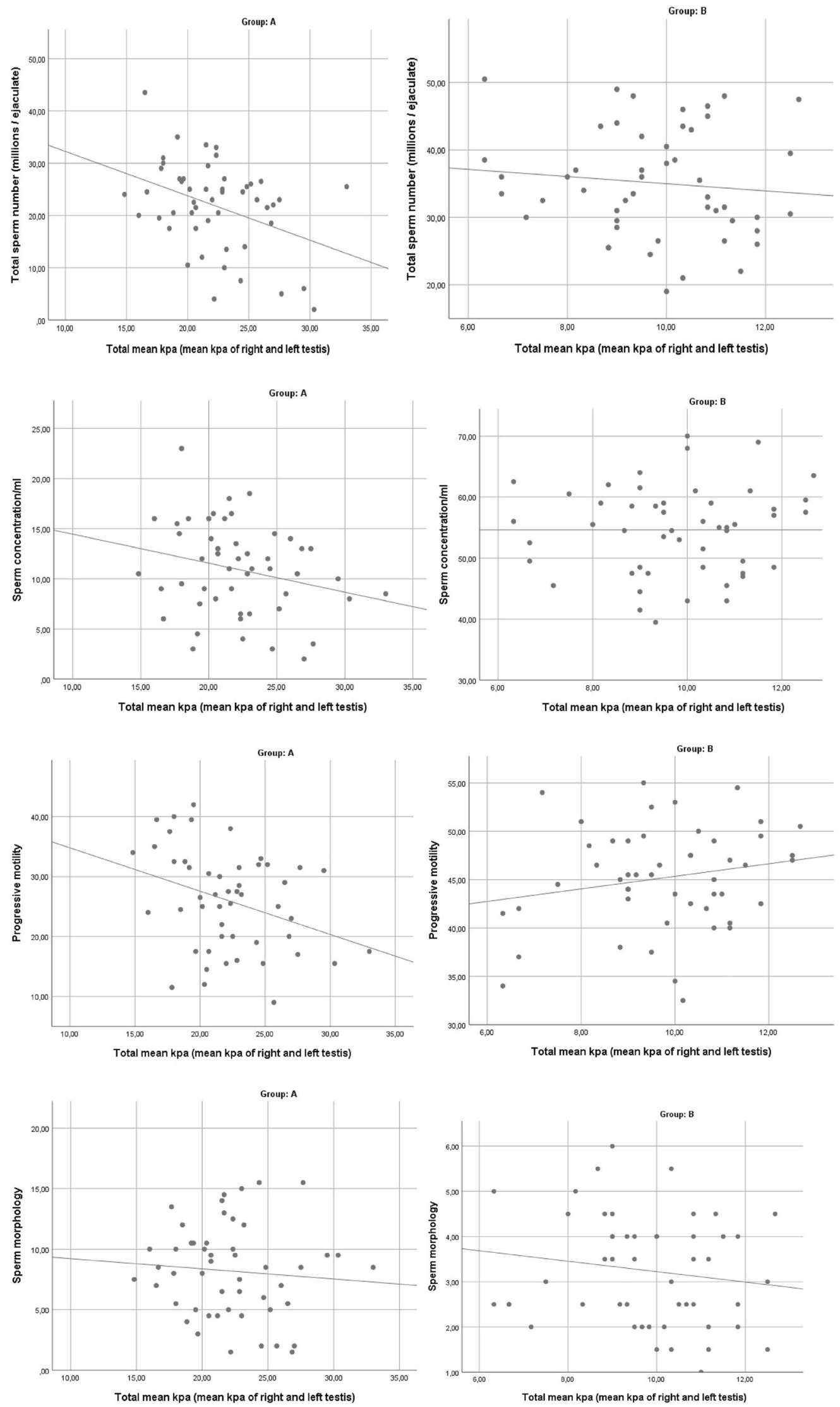

Fig. 4 Correlation between testicular stiffness and seminal analysis values of patients in groups A and B 
Table 6 Stiffness value to the upper right and left poles, lower right and left poles, medial right and left region in the two subgroups A and $\mathrm{B}$

\begin{tabular}{|c|c|c|c|c|}
\hline Group & $N$ & Mean & Std. deviation & $p$ value \\
\hline \multicolumn{5}{|c|}{ Left lower pole } \\
\hline A & 50 & 22.88 & 11.36 & \multirow[t]{2}{*}{$0.0001^{*}$} \\
\hline B & 50 & 8.04 & 3.56 & \\
\hline \multicolumn{5}{|c|}{ Left upper pole } \\
\hline A & 50 & 22.00 & 7.90 & \multirow[t]{2}{*}{$0.0001 *$} \\
\hline B & 50 & 10.28 & 2.86 & \\
\hline \multicolumn{5}{|c|}{ Left medial } \\
\hline A & 50 & 21.48 & 5.45 & \multirow[t]{2}{*}{$0.0001 *$} \\
\hline B & 50 & 9.94 & 1.61 & \\
\hline \multicolumn{5}{|c|}{ Right lower pole } \\
\hline A & 50 & 24.02 & 9.07 & \multirow[t]{2}{*}{$0.0001 *$} \\
\hline B & 50 & 10.08 & 5.47 & \\
\hline \multicolumn{5}{|c|}{ Right medial } \\
\hline A & 50 & 22.91 & 4.89 & \multirow[t]{2}{*}{$0.0001^{*}$} \\
\hline B & 50 & 9.59 & 2.45 & \\
\hline \multicolumn{5}{|c|}{ Right lower pole } \\
\hline A & 50 & 24.02 & 9.07 & \multirow[t]{2}{*}{$0.0001 *$} \\
\hline B & 50 & 10.08 & 5.47 & \\
\hline
\end{tabular}

SWE is a non-invasive, inexpensive, and a well-tolerated diagnostic procedure. In fact, SWE could represent a more accurate method to evaluate testicular parenchymal stiffness than the testicular palpation method performed during the physical examination to assess parenchymal elasticity. Zhang et al. demonstrated by SWE that in rabbits with testicular damage (following artificial testicular torsion and subsequently objectified by tissue biopsy) there was an increase in testicular rigidity. In addition, they found that the higher the stiffness values, the worse the spermatogenesis and morphology of the spermatozoa [21].

Findings presented by Yavuz et al. were similar to our results, showing that sperm count is inversely correlated with testicular stiffness value (expressed in $\mathrm{kPa}$ ), as they found a negative correlation between testicular values and sperm count with SWE. They concluded that testicular damage, on the one hand, decreased sperm count, and on the other hand, increased testicular $\mathrm{kPa}$. Our study made an extra leap since the study by Yavuz et al. did not compare the results with those of a control group and also did not exclude patients potentially affected by testicular pathologies that could generate enrollment bias [11].

Rocher et al. performed a study that identified infertile patients in various groups: OAT syndrome, obstructive azoospermia, Klinefelter syndrome non-obstructive azoospermia (KS-NOA), non-Klinefelter syndrome non-obstructive azoospermia (NOA), and varicocele [12]. They found that
Table 7 Differences stiffness in the same testis in regional part (upper. medial and lower) in both group A and group B

\begin{tabular}{|c|c|c|c|}
\hline & Mean & Std. deviation & $p$ value \\
\hline \multicolumn{4}{|l|}{ Group A } \\
\hline Right upper pole & 23.44 & 8.67 & 0.756 \\
\hline Right lower pole & 24.02 & 9.07 & \\
\hline Right upper pole & 23.44 & 8.67 & 0.601 \\
\hline Right medial & 22.91 & 4.89 & \\
\hline Right lower pole & 24.02 & 9.07 & 0.295 \\
\hline Right medial & 22.91 & 4.89 & \\
\hline Left upper pole & 22.00 & 7.90 & 0.635 \\
\hline Left lower pole & 22.88 & 11.36 & \\
\hline Left upper pole & 22.00 & 7.90 & 0.595 \\
\hline Left medial & 21.48 & 5.45 & \\
\hline Left lower pole & 22.88 & 11.36 & 0.229 \\
\hline Left medial & 21.48 & 5.45 & \\
\hline \multicolumn{4}{|l|}{ Group B } \\
\hline Left upper pole & 10.28 & 2.86 & 0.082 \\
\hline Left lower pole & 8.90 & 3.56 & \\
\hline Left upper pole & 10.28 & 2.86 & 0.295 \\
\hline Left medial & 9.94 & 1.61 & \\
\hline Left lower pole & 8.90 & 3.56 & 0.061 \\
\hline Left medial & 9.94 & 1.61 & \\
\hline Right upper pole & 10.52 & 4.41 & 0.361 \\
\hline Right lower pole & 10.08 & 5.47 & \\
\hline Right upper pole & 10.52 & 4.41 & 0.052 \\
\hline Right medial & 9.59 & 2.45 & \\
\hline Right lower pole & 10.08 & 5.47 & 0.425 \\
\hline Right medial & 9.59 & 2.45 & \\
\hline
\end{tabular}

KS-NOA patients had higher stiffness values than the NOA group. This is probably because the Leydig cell hyperplasia cluster may cause the formation of micronodules and, therefore, lead to a higher stiffness [22]. In our study, we excluded patients with Klinefelter syndrome to avoid bias related to histological changes in these patients.

Moreover, contrary to the study performed by Rocher et al., we excluded patients diagnosed with varicocele. In fact, this pathology could affect testicular elasticity. Dede et al. demonstrated a decrease in testicular elasticity in patients with varicocele [9].

The strengths of this study were the case-control prospective design and the measurement of the value of the testicular stiffness in three ROIs (1/3 upper pole, $1 / 3$ central zone, $1 / 3$ lower pole) for a greater accuracy of the measurements, since there is no agreement among the studies regarding which part of the testes should be used for the measurement.

In addition, the presence of another urologist experienced in SWE who evaluated the measurements helped ensure that the measurements were accurate. 

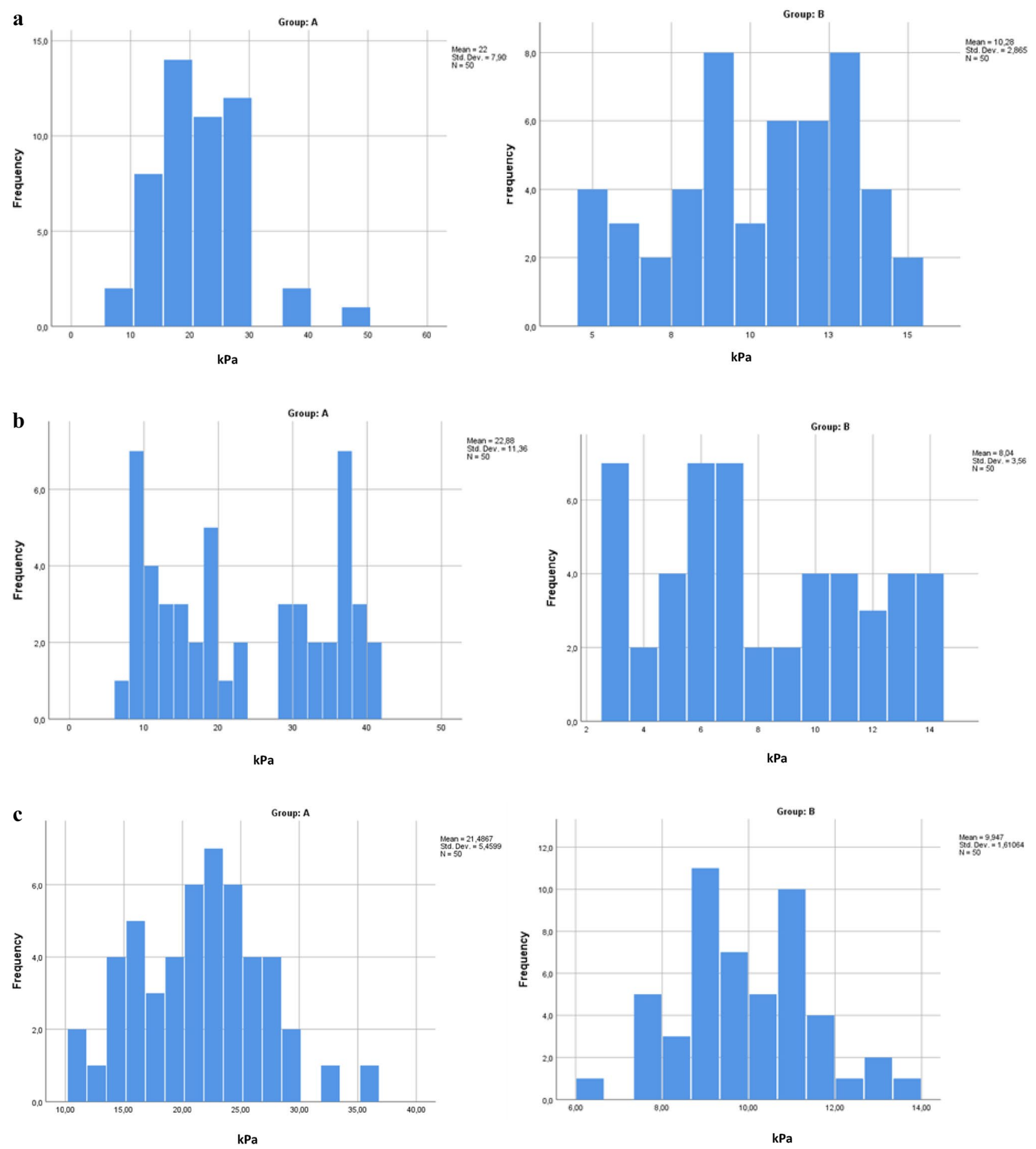

Fig. 5 Frequency of left testis stiffness values found in the upper pole (a), lower pole (b), and medial region (c) of both groups A and B

Limitations of this study included the lack of histopathologic data obtained from testicular biopsies and the small sample size. In addition, hormonal determinations of the participants were not evaluated.

\section{Conclusions}

SWE is an easy, reproducible, operator-independent, noninvasive, and inexpensive technique that provides information about the male gonads and their functionality. It is able 

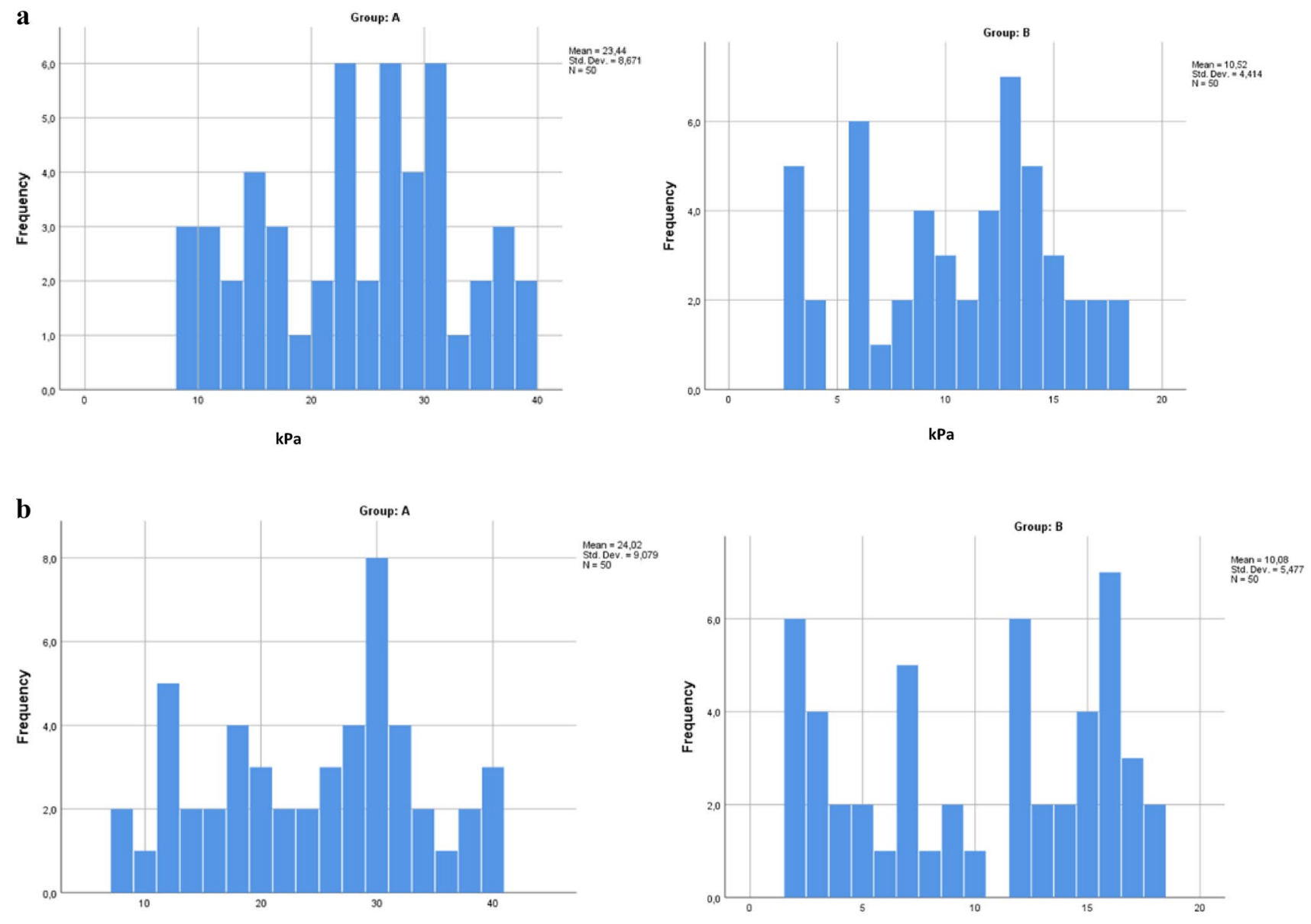

$\mathrm{kPa}$

kPa
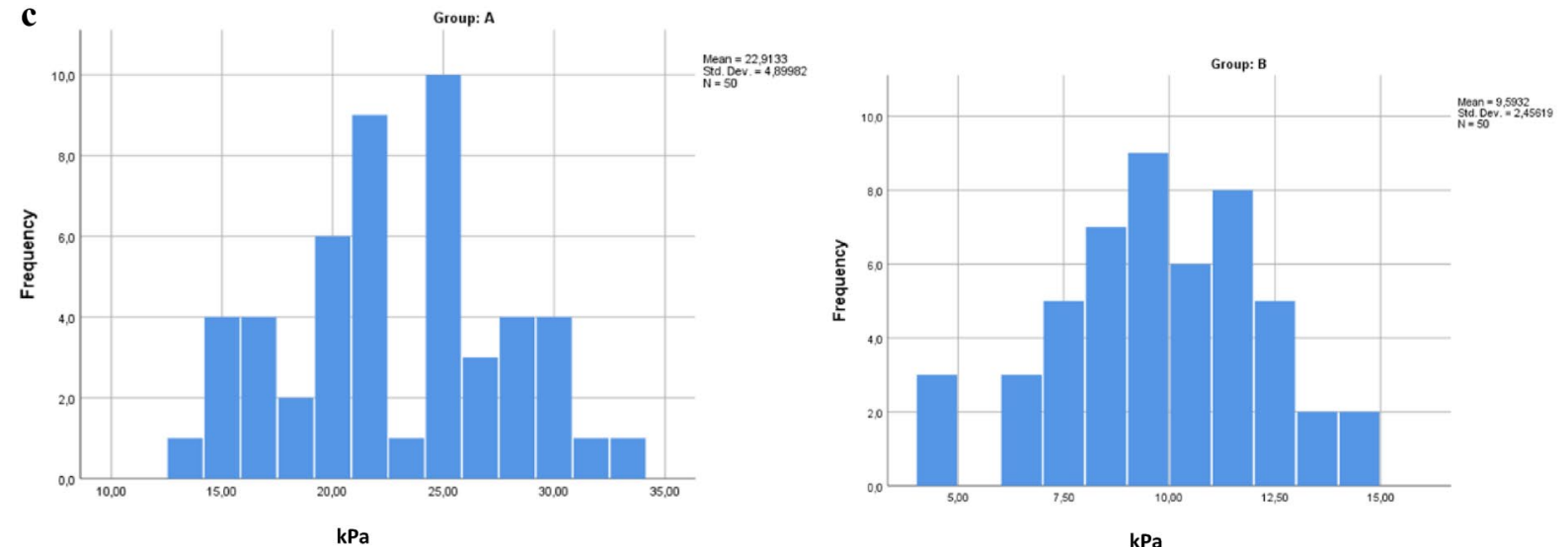

$\mathrm{kPa}$

Fig. 6 Frequency of right testis stiffness values found in the upper pole (a), lower pole (b), and medial region (c) of both groups A and B

to differentiate between the testicles capable of performing spermatogenesis and testicles with spermatic problems. Moreover, with the possibility of obtaining an absolute value, expressed in $\mathrm{kPa}$, it is possible to follow the evolution of OAT syndrome and to compare the values obtained after pharmacologic therapy. SWE is a promising technique to aid in the diagnosis of OAT in male infertile patients. 
Author contributions EI study conception and design; analysis and interpretation of results; FT study conception and design; draft manuscript preparation; data collection; AR data collection; GR data collection; FR data collection; FI analysis and interpretation of results; EC analysis and interpretation of results; All authors reviewed the results and approved the final version of the manuscript.

Funding Open access funding provided by Università degli Studi di Perugia within the CRUI-CARE Agreement.

\section{Declarations}

Conflict of interest The authors have no conflicts of interest to declare that are relevant to the content of this article.

Ethics approval All procedures performed in studies involving human participants were in accordance with the ethical standards of the institutional and with 1964 Helsinki Declaration and its later amendments or comparable ethical standards. The study was approved by the local ethics committee (CER 3767/20).

Consent to participate Informed consent was obtained from all individual participants included in the study.

Consent for publication Patients signed informed consent regarding publishing their data.

Open Access This article is licensed under a Creative Commons Attribution 4.0 International License, which permits use, sharing, adaptation, distribution and reproduction in any medium or format, as long as you give appropriate credit to the original author(s) and the source, provide a link to the Creative Commons licence, and indicate if changes were made. The images or other third party material in this article are included in the article's Creative Commons licence, unless indicated otherwise in a credit line to the material. If material is not included in the article's Creative Commons licence and your intended use is not permitted by statutory regulation or exceeds the permitted use, you will need to obtain permission directly from the copyright holder. To view a copy of this licence, visit http://creativecommons.org/licenses/by/4.0/.

\section{References}

1. Ombelet W, Cooke I, Dyer S, Serour G, Devroey P (2008) Infertility and the provision of infertility medical services in developing countries. Hum Reprod Update 14:605-621

2. Katz DJ, Teloken P, Shoshany O (2017) Male infertility-the other side of the equation. Aust Fam Physician 46:641-646

3. Armstrong JM, Keihani S, Hotaling JM (2018) Use of ultrasound in male infertility: appropriate selection of men for scrotal ultrasound. Curr Urol Rep 19(8):58

4. Sugimoto K, Moriyasu F, Oshiro H et al (2018) Viscoelasticity measurement in rat livers using shear-wave US elastography. Ultrasound Med Biol 44:2018-2024

5. Evans A, Whelehan P, Thomson K et al (2010) Quantitative shear wave ultrasound elastography: initial experience in solid breast masses. Breast Cancer Res 12:R104

6. Marsaud A, Durand M, Raffaelli C et al (2015) Elastography shows promise in testicular cancer detection. Prog Urol 25:75-82
7. Kantarci F, Cebi Olgun D, Mihmanli I (2012) Shear-wave elastography of segmental infarction of the testis. Korean J Radiol $13: 820-822$

8. Sun Z, Xie M, Xiang F et al (2015) Utility of real-time shear wave elastography in the assessment of testicular torsion. PLoS ONE 10:e0138523

9. Dede O, Teke M, Daggulli M et al (2016) Elastography to assess the effect of varicoceles on testes: a prospective controlled study. Andrologia 48:257-261

10. Roy C, de Marini P, Labani A, Leyendecker P, Ohana M (2020) Shear-wave elastography of the testicle: potential role of the stiffness value in various common testicular diseases. Clin Radiol 75:560.e9-560.e17

11. Yavuz A, Yokus A, Taken K et al (2018) Reliability of testicular stiffness quantification using shear wave elastography in predicting male fertility: a preliminary prospective study. Med Ultrason 20:141-147

12. Rocher L, Criton A, Gennisson JL et al (2017) Testicular shear wave elastography in normal and infertile men: a prospective study on 601 patients. Ultrasound Med Biol 43:782-789

13. Cooper TG, Noonan E, von Eckardstein S et al (2010) World Health Organization reference values for human semen characteristics. Hum Reprod Update 16:231-245

14. Brugh VM 3rd, Lipshultz LI (2004) Male factor infertility: evaluation and management. Med Clin N Am 88(2):367-385. https:// doi.org/10.1016/S0025-7125(03)00150-0 (PMID: 15049583)

15. Keijzer LBH, Strachinaru M, Bowen DJ et al (2019) Reproducibility of natural shear wave elastography measurements. Ultrasound Med Biol 45(12):3172-3185. https://doi.org/10.1016/j.ultrasmedb io.2019.09.002 (Epub 2019 Sep 26 PMID: 31564460)

16. Illiano E, Trama F, Ruffo A, Romeo G, Riccardo F, Iacono F, Costantini E (2021) Shear wave elastography as a new non-invasive diagnostic modality for the diagnosis of penile elasticity: a prospective multicenter study. Ther Adv Urol 13:1-8. https://doi.org/ $10.1177 / 17562872211007978$

17. Zaleska-Dorobisz U, Kaczorowski K, Pawluś A et al (2014) Ultrasound elastography—review of techniques and its clinical applications. Adv Clin Exp Med 23(4):645-655. https://doi.org/ 10.17219/acem/26301 (PMID: 25166452)

18. Cavallini G (2006) Male idiopathic oligoasthenoteratozoospermia. Asian J Androl 8:143-157

19. Ehala-Aleksejev K, Punab M (2017) Relationships between total testicular volume, reproductive parameters and surrogate measures of adiposity in men presenting for couple's infertility. Andrologia 50(4):e12952

20. Erdoğan H, Durmaz MS, Özbakır B et al (2020) Experience of using shear wave elastography in evaluation of testicular stiffness in cases of male infertility. J Ultrasound 23:529-534

21. Zhang X, Lv F, Tang J (2015) Shear wave elastography (SWE) is reliable method for testicular spermatogenesis evaluation after torsion. Int J Clin Exp Med 8:7089-7097

22. Aksglaede L, Skakkebaek NE, Almstrup K, Juul A (2011) Clinical and biological parameters in 166 boys, adolescents and adults with nonmosaic Klinefelter syndrome: a Copenhagen experience. Acta Paediatr 100:793-806

Publisher's Note Springer Nature remains neutral with regard to jurisdictional claims in published maps and institutional affiliations. 